An interesting unsolved problem is the following: Is the sum of the relative widths always greater than or equal to 1 , when a convex body is covered by strips (relative width of a strip = width of the strip divided by the width in the same direction of the convex body)?

COPENHAGEN University AND

RICE INSTITUTE

\title{
ERRATA, VOLUME 2
}

Jack Levine, Collineations in generalized spaces.

p. 455 , reference 6 . For "1928" read "1929."

J. L. Walsh, On Rouchê's theorem and the integral-square measure of approximation.

p. 673, line 11. For " $\sum\left|a z_{n}\right|^{2 "} \operatorname{read}$ " $\sum\left|a_{n}\right|^{2}$." 